\title{
The Effectiveness of Virtual Reality-Based Interventions in Rehabilitation Management of Breast Cancer Survivors: Systematic Review and Meta-analysis
}

Xiaofan $\mathrm{Bu}^{1}$, MSc; Peter H F Ng${ }^{2}$, PhD; Wenjing Xu${ }^{3}$, MSc; Qinqin Cheng ${ }^{4}$, PhD; Peter Q Chen ${ }^{2}$, MSc; Andy S K Cheng ${ }^{5}, \mathrm{PhD}$; Xiangyu Liu ${ }^{6}, \mathrm{PhD}$

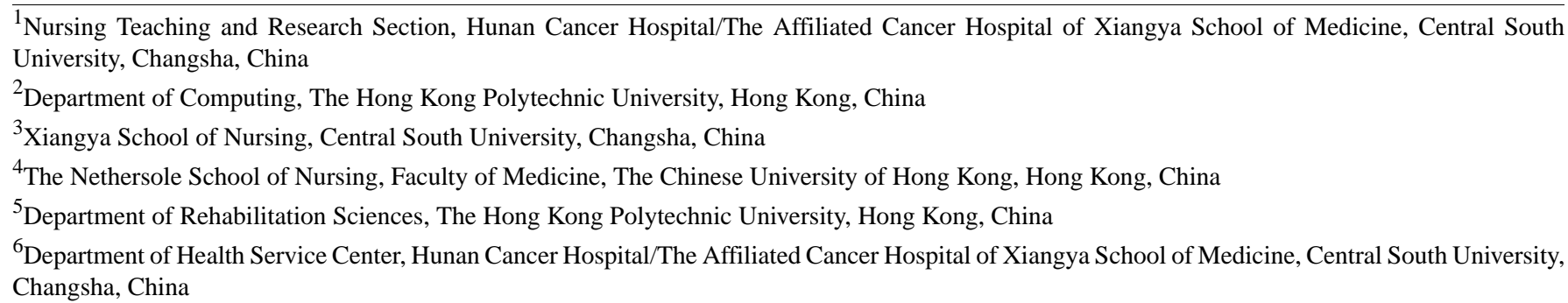

\section{Corresponding Author:}

Xiangyu Liu, PhD

Department of Health Service Center

Hunan Cancer Hospital/The Affiliated Cancer Hospital of Xiangya School of Medicine

Central South University

Number 283, Tongzi Road

Changsha, 410013

China

Phone: 8618674869736

Email:979596459@qq.com

\section{Abstract}

Background: Breast cancer survivors (BCSs) can present with various physical and psychological symptoms and functional deficits that impact their quality of life. Virtual reality (VR) technology is being used in breast cancer rehabilitation management to improve the emotional, cognitive, and physical well-being of BCSs.

Objective: This systematic review aimed to examine the effectiveness of VR-based interventions on health-related outcomes in BCSs. A meta-analysis was conducted to evaluate the effectiveness of VR-based interventions in the rehabilitation management of BCSs.

Methods: A systematic search was conducted on PubMed, Web of Science, EMBASE, CINAHL with Full Text, the Cochrane Central Register of Controlled Trials, CNKI, WanFang, VIP, and CBM, from inception to May 25, 2021. The inclusion criteria of the selected studies were as follows: (1) adults diagnosed with breast cancer; (2) any type of VR-based interventions (immersive and nonimmersive virtual environment); (3) comparison of traditional rehabilitation methods; (4) outcomes including pain, depression, anxiety, fatigue, cognitive function, shoulder range of motion (ROM), hand grip strength, lymphedema, cybersickness symptoms, fear of movement, bleeding, effusion, and flap necrosis, both during and after treatment; and (5) randomized controlled trials (RCTs), case-controlled trials, and quasi-experimental studies. The Cochrane Collaboration Tool was used to evaluate the risk of bias. Review Manager version 5.3 (Cochrane Collaboration) was used to conduct the meta-analysis. The mean difference (MD) and SDs with 95\% CIs were used to calculate continuous variables.

Results: Twelve articles were included in this systematic review, of which 10 contributed information to the meta-analysis. A total of 604 participants were analyzed. The statistical analysis showed significant results for flexion (standard mean difference [SMD] 1.79; $95 \%$ CI 0.55 to 3.03; $P=.005$ ), extension (SMD 1.54; $95 \%$ CI 0.83 to $2.25 ; P<.001$ ), abduction (MD $17.53 ; 95 \%$ CI 14.33 to $20.72 ; P<.001$ ), adduction (MD 15.98; $95 \%$ CI 14.02 to $17.94 ; P<.001$ ), internal rotation (MD $7.12 ; 95 \%$ CI 5.54 to $8.70 ; P<.001$ ), external rotation (SMD $0.96 ; 95 \%$ CI 0.62 to $1.29 ; P<.001$ ), anxiety (MD $-6.47 ; 95 \%$ CI -7.21 to $-5.73 ; P<.001$ ), depression (MD $-4.27 ; 95 \% \mathrm{CI}-4.64$ to $-3.91 ; P<.001$ ), pain (MD $-1.32 ; 95 \% \mathrm{CI}-2.56$ to $-0.09 ; P=.04)$, and cognitive function 
(MD 8.80; 95\% CI 8.24 to 9.36; $P<.001)$. The meta-analysis indicated little to no difference in hand grip strength (MD 1.96; $95 \%$ CI -0.93 to $4.85 ; P=.18)$.

Conclusions: Findings of this review noted a weak but consistent positive association between VR-based interventions and outcomes. However, these results must be interpreted with caution due to the limited number of controlled trials analyzed, small sample sizes, and poor methodological quality. Well - designed, large, high - quality trials may have a significant impact on our confidence in the results. Future studies should identify specific aspects that improve the clinical impact of VR-based interventions on major outcomes in BCSs in the clinical setting.

Trial Registration: PROSPERO International Prospective Register of Systematic Reviews CRD42021250727; https://tinyurl.com/2p89rmnk

(JMIR Serious Games 2022;10(1):e31395) doi: $\underline{10.2196 / 31395}$

\section{KEYWORDS}

virtual reality; rehabilitation management; symptom; motor function; systematic review; meta-analysis

\section{Introduction}

Female breast cancer has surpassed lung cancer as the most commonly diagnosed cancer worldwide, with an estimated 2.3 million new cases in 2020 [1]. The 5-year relative survival rate for individuals with breast cancer is $82 \%$ [2]. An increasing number of patients with breast cancer have prolonged life following treatment; however, they can suffer from numerous physical and psychological symptoms (ie, pain, fatigue, depressive symptoms, anxiety, lymphedema), functional deficits (ie, cognitive impairment, reduced shoulder range of motion [ROM]), and complications (ie, bleeding, effusion, flap necrosis) during and after treatment, which can greatly affect their quality of life [3-5].

While chemotherapy improves the survival rate of patients with cancer, the potential adverse effects of chemotherapy limit the dose and treatment continuation. To some extent, adverse effects can aggravate patients' emotional distress. Emotional distress mainly includes fatigue, pain, anxiety, and depression, which is commonplace in cancer populations [6]. Distress was designated as the sixth vital sign in 2005 in Canada [7] associated with a reduction in overall quality of life among patients with cancer [8]. Cancer-related fatigue is also distressing, persistent, and related to a subjective sense of physical, emotional, or cognitive tiredness or exhaustion related to cancer or cancer treatment, which is not proportional to recent activity and interferes with general functioning [9]. The level of cancer-related fatigue peaks during breast cancer therapy, and the prevalence of chronic fatigue increases after treatment [10]. The prevalence rates of severe fatigue range from $7 \%$ to $52 \%$, with a pooled prevalence of $26.9 \%$. Risk factors of fatigue were higher disease stages, chemotherapy, and receiving the combination of surgery, radiotherapy, and chemotherapy, both with and without hormone therapy [11]. Patients with anemia are prone to fatigue owning to the reduced hemoglobin level after chemotherapy [12]. The prevalence of depression symptoms varies from $9.4 \%$ to $66.1 \%$, whereas that of anxiety ranges from $17.9 \%$ to $33.3 \%$ [13]. Age, place of residence, marital status, educational level, religion, stage of cancer, and current activity burden of symptoms were found to be factors associated with the risk of anxiety and depression [8]. Anxiety did not show greater prevalence among women with early stage breast cancer in comparison to the general female population
[13]. Breast cancer survivors (BCSs) have been shown to have an increased risk of depression 1 year after diagnosis, which decreases over the ensuing years [13]. Early interventions can improve treatment tolerance, which could be crucial to increase the chances of recovery [14]. Virtual reality (VR) is the use of computer technology to create an interactive 3D world by visual, audio, and touch simulation, where an individual has a sense of spatial presence. VR could be a promising strategy to improve chemotherapy tolerance by distraction. VR can include immersive or nonimmersive systems. With full immersive systems, the patient is enveloped in a computer-generated virtual world by using a head-mounted display and has opportunities to interact with and control the virtual environment (eg, relaxing landscapes, deep sea diving, the weather, plants/trees, or flowers) [15-17]. With nonimmersive systems, the patient is connected to the virtual world (eg, emotional parks and walk through nature) by an external monitor but can still communicate with the real world [18]. Nonimmersive system is intuitive and easy to use [18].

Pain related to cancer is a distressing experience, with sensory, emotional, cognitive, and social components [19,20]. The prevalence of persistent postsurgical pain in BCSs ranges from $2 \%$ to $78 \%$ [21]. Fear of movement further increases the risk of decline in upper limb function in BCSs [22]. However, avoiding movements that are likely to induce pain may aggravate upper limb dysfunction. VR exposure can target cognitive and affective pain pathways [23] and can decrease pain intensity, distress, and anxiety by altering how pain signals are processed in the central nervous system [23]. This is achieved by a series of mechanisms, including attentional distraction, conditioning of VR imagery, and reduced pain [23].

BCSs are at a lifelong risk for the development of breast cancer-related lymphedema (BCRL) [24], which has an incidence of $21.4 \%$ [25]. There is strong evidence that higher BMI, larger number of dissected nodes, certain chemotherapy agents (eg, taxane-based regimen), the extent of surgery (eg, total mastectomy), larger irradiation field, and sedentary lifestyles are associated with BCRL [25-27]. Disruption of the lymphatic system after surgery or radiation treatment results in the accumulation of lymph fluid causing BCRL [28]. BCRL is a chronic, potentially debilitating condition that involves progressive swelling, limited ROM, and feelings of pain and numbness, and requires lifelong symptom management [24]. 
Resistance exercise ameliorates symptoms in patients with established lymphedema [29]. VR-based rehabilitation systems (eg, Xbox 360 Kinect games, the BrightArm Duo Rehabilitation System) have been identified to be effective for patients with weak arms and diminished grasping ability [22,30]. These systems use VR to engage the patient in upper body bimanual exercises. Moreover, the BrightArm Duo Rehabilitation System simultaneously provides cognitive training and affective relief via custom integrative rehabilitation games. Cancer-related cognitive impairment is characterized as deficits in areas of cognition, including memory, attention, information processing speed, and executive function [31,32]. Between $15 \%$ and $50 \%$ of individuals with breast cancer who receive chemotherapy experience persisting cognitive impairment [33], often referred to as "chemobrain" [34]. The duration of symptoms may extend for years after the completion of treatment [31]. The rapid development of VR promotes the combination of functional rehabilitation and cognitive exercises at a higher level, where patients can receive bimanual and cognitive exercises simultaneously.

However, it is unclear whether VR-based interventions could promote the rehabilitation management of BCSs. Additionally, until now, no systematic reviews or meta-analyses have investigated the association between VR and rehabilitation management of BCSs. Therefore, in this systematic review and meta-analysis, we will qualitatively and quantitatively examine the effects of VR-based interventions on BCSs.

\section{Methods}

\section{Overview and Registration}

This systematic review conforms to the Preferred Reporting Items for Systematic Reviews and Meta-Analyses (PRISMA) statement [35] and was registered in advance in the international Prospective Register of Systematic Reviews (PROSPERO) database (registration number CRD42021250727).

\section{Search Strategy}

The literature search was conducted on PubMed, Web of Science, EMBASE, CINAHL with Full Text, the Cochrane Central Register of Controlled Trials, CNKI, WanFang, VIP, and CBM, from inception to May 25, 2021. The search terms were chosen to be inclusive of VR (eg, "virtual reality", "VR", "virtual environment") and breast cancer (eg, "breast neoplasm" OR "breast tumors"). Medical Subject Headings (MeSH) and Embase Subject Headings terms were used. See Multimedia Appendix 1 for the specific search strategy adapted for each database. Details of the search strings of the PubMed database are displayed in Table 1. Searches were limited to English and Chinese language sources.

Table 1. Search strategy in PubMed.

\begin{tabular}{|c|c|}
\hline Strategy & Search string \\
\hline 1 & "Virtual Reality”[Mesh] OR VR OR “virtual reality" OR “virtual environment” OR "head-mounted display” OR “virtual reality goggle" \\
\hline 2 & $\begin{array}{l}\text { "Breast Neoplasms"[Mesh] OR "breast neoplasms" OR "breast neoplasm" OR "breast tumors" OR "breast tumor" OR "breast cancer" } \\
\text { OR "mammary cancer" OR "mammary cancers" OR "Breast Malignant Neoplasm" OR "Breast Malignant Neoplasms" OR "Malignant } \\
\text { Tumor of Breast" OR "Breast Malignant Tumor" OR "Breast Malignant Tumors" OR "Cancer of Breast" OR "Cancer of the Breast" OR } \\
\text { "Mammary Carcinoma" OR "Human Mammary Carcinomas" OR "Human Mammary Carcinoma" OR "Mammary Neoplasms" OR } \\
\text { "Human Mammary Neoplasm" OR "Human Mammary Neoplasms" OR "Mammary Neoplasm" OR "Breast Carcinoma” OR "Breast } \\
\text { Carcinomas" }\end{array}$ \\
\hline 3 & \#1 AND \#2 \\
\hline
\end{tabular}

\section{Selection Criteria}

The Population, Intervention, Comparison, Outcomes, and Study design (PICOS) model was used to establish the article inclusion criteria:

- Population: adults diagnosed with breast cancer;

- Intervention: any type of VR-based interventions (immersive and nonimmersive virtual environment);

- Comparison: traditional rehabilitation methods (including interventions under the guidance of medical staff or watching videos) or nonintervention;

- Outcomes: outcomes specifically related to rehabilitation management, such as pain, depression, anxiety, fatigue, cognitive function, shoulder ROM, hand grip strength, lymphedema, cybersickness symptoms, fear of movement, bleeding, effusion, and flap necrosis after surgery; and

- Study design: randomized controlled trials (RCTs), case-controlled trials, and quasi-experimental studies.

Studies were excluded if they (1) did not specify the type of cancer; (2) described the technologies only; (3) were conference papers, workshop papers, literature reviews, posters, comments, letters, study protocols, or proceedings papers.

\section{Selection Process}

Records from searches were imported into an EndNote library (EndNote X9.1) and duplicate studies were removed. The remaining records were transferred into an Excel spreadsheet (Microsoft). Screening was conducted by 2 independent reviewers (XB and WX) who assessed the article titles, abstracts, and full texts. Articles that did not meet the established inclusion criteria were excluded. Any disagreements between the 2 reviewers were resolved by discussion or in consultation with other investigators (QC, $\mathrm{AC}$, and $\mathrm{XL})$.

\section{Data Extraction}

Data extraction was performed independently by 2 reviewers (XB and WX) using a predesigned standardized form in Word (Microsoft). Any discrepancies between the 2 reviewers were resolved by discussion with other reviewers (QC, AC, and XL), who acted as arbiters where necessary. We removed duplicate data published in different manuscripts. Additionally, the authors 
of the included trials were contacted to obtain any unclear or missing data. Data extraction included study characteristics (the first author, study design, and study region), participant characteristics (sample size, age), intervention details (characteristics of interventions, duration), patient-important outcomes, measuring instrument, and main results.

\section{Risk of Bias Assessment}

Two reviewers (XB and WX) independently assessed the methodological quality of all included trials. The Cochrane risk-of-bias tool was used to assess the quality of included RCTs [36]. The Cochrane risk-of-bias tool includes 6 domains of bias: selection bias, performance bias, detection bias, attrition bias, reporting bias, and other bias. After assessing the risk of bias of each study, the studies were categorized as "low risk," "high risk," or "unclear risk." The Risk Of Bias In Non-randomized Studies of Interventions (ROBINS-I) was used to assess the quality of the included non-RCTs, covering 7 distinct domains: bias due to confounding, selection bias, bias in measurement classification of interventions, bias due to deviations from intended interventions, bias due to missing data, bias in the measurement of outcomes, and bias in the selection of the reported result [37]. The ROBINS-I is a new tool for evaluating the risk of bias in estimates of the comparative effectiveness (harm or benefit) of interventions from studies that do not use randomization to allocate units (individuals or clusters of individuals) to comparison groups [37]. After assessing the risk of bias of each study, the studies were categorized as "low risk of bias," "moderate risk of bias," "serious risk of bias," "critical risk of bias," or "no information." In case of doubt, the final decision was determined through discussion or consultation with other reviewers (QC, AC, and XL).

\section{Meta-analysis}

The meta-analysis compared VR interventions with other interventions or nonintervention. The studies were divided into subgroups based on the measuring instrument that was used in the study. If more than 1 instrument was used in the same study, we included the study in more than 1 subgroup. The differences in the effect size between the groups were analyzed in terms of the standardized mean difference (SMD). Review Manager version 5.3 (Cochrane Collaboration) was used to conduct a meta-analysis. The mean difference (MD) and SDs with $95 \%$ CIs were used to calculate continuous variables. Initially, a fixed-effect model was used in the data analysis. An $I^{2}$ value over 0.5 was considered to represent substantial heterogeneity and a random-effect model was used [38]. Subgroup analyses were not possible due to the lack of patient-level data. All $P$ values were 2 sided.

\section{Results}

\section{Search Output}

A total of 964 potentially relevant articles were initially identified from the 9 databases; 271 articles were removed due to duplication, and the remaining 693 studies were screened. We excluded 664 articles due to insufficient relevance based on the title and abstract. The characteristics of the excluded studies are shown in the PRISMA diagram (Figure 1). Twelve studies were included in the systematic review, 10 of which were further included in the meta-analysis. 
Figure 1. PRISMA (Preferred Reporting Items for Systematic Reviews and Meta-Analyses) flowchart.

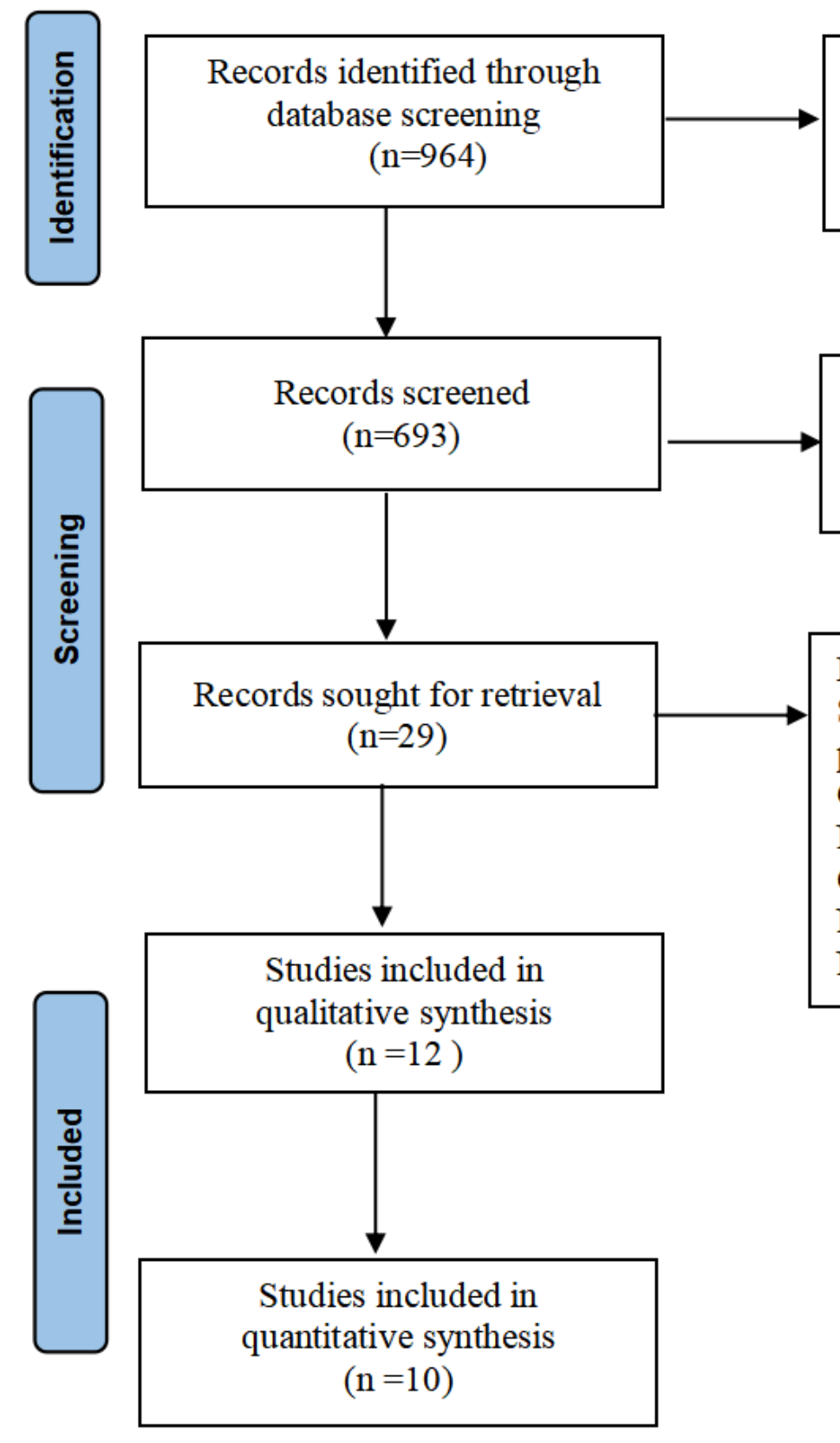

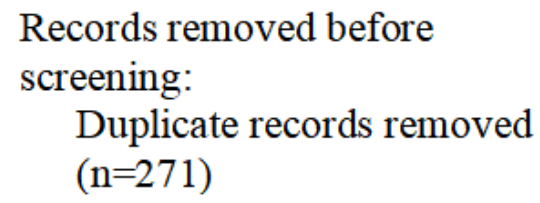

Records removed before screening:

Duplicate records removed $(\mathrm{n}=271)$

Records excluded after screening the title or abstract $(n=664)$

Full-text excluded ( $\mathrm{n}=17$ ):

Studies not focus on breast cancer patients $(n=6)$ Conference proceeding $(\mathrm{n}=2)$

Not related to the target outcomes $(n=4)$ Qualitative research $(\mathrm{n}=2)$ Non-English or Chinese Studies $(\mathrm{n}=1)$ Not a controlled trail $(n=2)$

\section{Characteristics of the Included Studies}

The characteristics of the 12 studies are shown in Table 2. Three studies were from the United States, 3 from China, and 1 each from Turkey, Italy, Egypt, France, Australia, and Jordan. The included studies were published between 2003 and 2021 [14-17,23,30,39-44]. Of the 12 studies, 6 were RCTs [15,16,23,41-43], 2 were quasi-experimental design studies $[39,40], 1$ was an externally controlled trial [14], and 3 $[17,30,44]$ were pre-posttest study designs with a single arm.
The number of participants ranged from 6 to 80 . All participants were adult patients with breast cancer or BCSs. VR-based interventions included both immersive and nonimmersive formats. The intervention duration varied from 15 minutes to 10 months. All studies examined the effects of VR-based interventions on health-related outcomes, including shoulder ROM, hand grip strength, anxiety, depression, pain reduction, cognitive function, fatigue, incidence of complications, cybersickness symptoms, and fear of movement. 
Table 2. Characteristics of the 12 studies.

\begin{tabular}{|c|c|c|c|c|c|c|}
\hline $\begin{array}{l}\text { Author [reference], } \\
\text { country }\end{array}$ & Study design & Study sample & $\begin{array}{l}\text { Intervention meth- } \\
\text { ods }\end{array}$ & Intervention duration & $\begin{array}{l}\text { Outcome/in- } \\
\text { strument }\end{array}$ & Main results \\
\hline $\begin{array}{l}\text { Feyzioğlu et al } \\
\text { [22], Turkey }\end{array}$ & $\mathrm{RCT}^{\mathrm{a}}$ & $\begin{array}{l}\text { Forty women with } \\
\text { breast cancer were ran- } \\
\text { domly assigned to the } \\
\text { experimental group (use } \\
\text { of Xbox } 360 \\
\text { Kinect-based VR }\end{array}$ & $\begin{array}{l}\text { Xbox } 360 \\
\text { Kinect-based VR } \\
\text { training: using } \\
\text { Kinect Sports I } \\
\text { (darts, bowling, box- } \\
\text { ing, beach volley- }\end{array}$ & $\begin{array}{l}\text { A total of } 6 \text { weeks of } \\
\text { exercising with the } \\
\text { Kinect (duration of } 35 \\
\text { minutes/day for } 2 \\
\text { days per week). }\end{array}$ & $\begin{array}{l}\text { VAS }^{\mathrm{c}}, \mathrm{ROM}^{\mathrm{d}} \text {, } \\
\text { arm strength, } \\
\text { DASH }^{\mathrm{e}} \text { ques- } \\
\text { tionnaire, } \\
\mathrm{TKS}^{\mathrm{f}}\end{array}$ & $\begin{array}{l}\text { Significant changes in } \\
\text { pain, ROM, muscle } \\
\text { strength, grip strength, } \\
\text { functionality, and } \\
\text { TKS scores after the } \\
\text { treatment }(P<.05) \text {. }\end{array}$ \\
\hline
\end{tabular}

$\begin{array}{llll}\text { Chirico et al [14], } & \begin{array}{l}\text { Externally } \\ \text { Italy }\end{array} & \begin{array}{l}\text { Patients were randomly } \\ \text { assigned to the VR or }\end{array} & \text { Vuzix Wrap } \\ & \text { 1200VR head- } \\ \text { music group (MT) and } & \text { mounted glasses } \\ & \text { were compared with a } & \text { with the Second Life } \\ \text { nonconcurrently recruit- } & \text { platform was used to } \\ \text { ed control group. Thirty } & \text { explore an island, } \\ \text { patients were included } & \text { walk through a for- } \\ & \text { in the VR intervention est, observe different } \\ & \text { group, 30 patients in the animals, climb a } \\ & \text { MT intervention group, mountain, and swim } \\ & \text { and 34 patients consti- in the sea. } \\ & \text { tuted the control group. }\end{array}$

Atef et al [39], Quasi-random- Fifteen participants

Egypt
Nintendo Wii game: tennis, triceps extension, and rhythmic boxing.
The duration of the VR-based therapy sessions included 30 minutes of training over a period of 4 weeks, with 2 sessions every week.
Patients used the equipment for 20 minutes during chemotherapy.

The duration of the
R-based therapy
minutes of training
ver a period of 4
weeks, with 2 sessions
very week.

Circumferential measurements, excess arm volume, QuickDASH9 scale muscular facilitation).

\section{$\mathrm{SAI}^{\mathrm{g}}, \mathrm{SV}-$ POMS $^{\text {h }}$, VRSQ $^{\mathrm{i}}$}

Buche et al [17], Pre-posttest France

$\begin{array}{ll}\text { Jimenez et al [40], } & \begin{array}{l}\text { Quasi-experi- } \\ \text { mental design } \\ \text { Australia }\end{array} \\ \text { study }\end{array}$

In a physiotherapy cen- The Greener ter, each of the 46 pa- Gamer's Nature tients participated in 4 experimental conditions in a random order: 2 sessions used virtual immersion (ie, 1 participatory and 1 contemplative), 1 session proposed musical listening, and the fourth was a standard session care.

Patients with breast cancer $(n=18)$ in the control group received the standard pre-RT ${ }^{1}$ education package at a targeted cancer therapy center. Patients with breast cancer $(\mathrm{n}=19)$ in the experimental group attended a

VERT $^{\mathrm{m}}$-based education session detailing RT immobilization, planning, and treatment. application has 9 re- physiotherapy center. laxing visual environments with relaxing sounds, including 2 immersive modes: contemplative mode and participatory mode.

The VERT education program incorporated low-level technical information about RT, patient anatomy, and radiation dose. Aspects of immobilization, simulation, planning, and treatment pertinent to patients with breast cancer were explored.

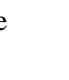

ITC-SOPI ${ }^{\mathrm{j}}$ feeling of elapsed time, SAI, QC ${ }^{\mathrm{k}}$

\section{perforned over a peri- Each session lasted an average 30 minutes. \\ The sessions were performed over od of 10 months in a}




\begin{tabular}{|c|c|c|c|c|c|c|}
\hline $\begin{array}{l}\text { Author [reference], } \\
\text { country }\end{array}$ & Study design & Study sample & $\begin{array}{l}\text { Intervention meth- } \\
\text { ods }\end{array}$ & Intervention duration & $\begin{array}{l}\text { Outcome/in- } \\
\text { strument }\end{array}$ & Main results \\
\hline $\begin{array}{l}\text { Bani et al [16], } \\
\text { Jordan }\end{array}$ & $\mathrm{RCT}$ & $\begin{array}{l}\text { Female patients with } \\
\text { breast cancer }(\mathrm{n}=80) \\
\text { were randomly assigned } \\
\text { to the intervention and } \\
\text { comparison groups. }\end{array}$ & $\begin{array}{l}\text { The intervention } \\
\text { group chose } 2 \text { scenar- } \\
\text { ios: deep sea diving } \\
\text { "Ocean Rift" or sit- } \\
\text { ting on the beach } \\
\text { with the "Happy } \\
\text { Place" track. }\end{array}$ & $\begin{array}{l}\text { The VR exposure ses- } \\
\text { sion was ended at the } \\
\text { peak time of painkiller } \\
\text { efficacy. }\end{array}$ & $\begin{array}{l}\text { VAS, SAI, } \\
\text { MMSE }^{\mathrm{o}}\end{array}$ & $\begin{array}{l}\text { One session of immer- } \\
\text { sive VR plus mor- } \\
\text { phine resulted in a } \\
\text { significant reduction } \\
\text { in pain and anxiety } \\
\text { self-reported scores, } \\
\text { compared with mor- } \\
\text { phine alone, in pa- } \\
\text { tients with breast can- } \\
\text { cer }(P<.05) \text {. }\end{array}$ \\
\hline $\begin{array}{l}\text { House et al [30], } \\
\text { USA }\end{array}$ & Pre-posttest & $\begin{array}{l}\text { Community-dwelling } \\
\text { women }(n=6) \text { with } \\
\text { postsurgical breast can- } \\
\text { cer pain in the upper } \\
\text { arm. }\end{array}$ & $\begin{array}{l}\text { The BrightArm Duo } \\
\text { Rehabilitation Sys- } \\
\text { tem consists of a } \\
\text { low-friction robotic } \\
\text { rehabilitation table, } \\
\text { computerized fore- } \\
\text { arm supports, a dis- } \\
\text { play, a laptop for the } \\
\text { therapist station, a } \\
\text { remote clinical serv- } \\
\text { er, and a library of } \\
\text { custom integrative } \\
\text { rehabilitation games. }\end{array}$ & $\begin{array}{l}\text { The duration of the } \\
\text { VR-based therapy } \\
\text { sessions progressed } \\
\text { from } 20 \text { to } 50 \text { min- } \\
\text { utes, twice a week for } \\
8 \text { weeks. }\end{array}$ & $\begin{array}{l}\text { BDI-II }^{\mathrm{p}}, \\
\text { BVMT-R }^{\mathrm{q}}, \\
\text { TMT-A }^{\mathrm{r}} \\
\text { TMT-B }^{\mathrm{s}} \\
\text { NAB }^{\mathrm{t}}, \\
\text { NPRS }^{\mathrm{u}}, \\
\text { HVLT-R }^{\mathrm{v}}, \\
\text { and PHQ-9 }\end{array}$ & $\begin{array}{l}\text { Pain intensity showed } \\
\text { a } 20 \% \text { downward } \\
\text { trend. Outcomes indi- } \\
\text { cate improvement in } \\
\text { cognition, shoulder } \\
\text { range, strength, func- } \\
\text { tion, and depression. }\end{array}$ \\
\hline $\begin{array}{l}\text { Schneider et al } \\
\text { [15], USA }\end{array}$ & $\begin{array}{l}\text { RCT: } \\
\text { crossover de- } \\
\text { sign }\end{array}$ & $\begin{array}{l}\text { A crossover design was } \\
\text { used to examine the ef- } \\
\text { fects of a VR distrac- } \\
\text { tion intervention on } \\
\text { chemotherapy-related } \\
\text { symptom distress levels } \\
\text { in } 16 \text { women aged } \geq 50 \\
\text { years. }\end{array}$ & $\begin{array}{l}\text { Participants chose } \\
\text { from } 3 \text { CD- } \\
\text { ROM-based scenar- } \\
\text { ios: Oceans Below, } \\
\text { A World of Art, or } \\
\text { Titanic: Adventure } \\
\text { Out of Time. }\end{array}$ & $\begin{array}{l}\text { Participants wore the } \\
\text { head-mounted device } \\
\text { during their intra- } \\
\text { venous chemotherapy } \\
\text { treatment. Each sce- } \\
\text { nario could last up to } \\
\text { several hours. }\end{array}$ & $\begin{array}{l}\text { MMSE, } \text { PFS }^{\mathrm{x}} \text {, } \\
\text { SAI, SDS }^{\mathrm{y}}\end{array}$ & $\begin{array}{l}\text { A significant decrease } \\
\text { in the SAI }(P=.10) \\
\text { scores was observed } \\
\text { immediately follow- } \\
\text { ing chemotherapy } \\
\text { treatments when par- } \\
\text { ticipants used VR. No } \\
\text { significant changes } \\
\text { were found in SDS or } \\
\text { PFS values. There } \\
\text { was a consistent trend } \\
\text { toward improved } \\
\text { symptoms on all mea- } \\
\text { sures } 48 \text { hours follow- } \\
\text { ing completion of } \\
\text { chemotherapy. }\end{array}$ \\
\hline $\begin{array}{l}\text { Schneider et al } \\
\text { [41], USA }\end{array}$ & $\begin{array}{l}\text { RCT: } \\
\text { crossover de- } \\
\text { sign }\end{array}$ & $\begin{array}{l}\text { A crossover design was } \\
\text { used to examine the ef- } \\
\text { fects of a VR distrac- } \\
\text { tion intervention on } \\
\text { chemotherapy-related } \\
\text { symptom distress levels } \\
\text { in } 20 \text { women aged 18- } \\
55 \text { years. }\end{array}$ & $\begin{array}{l}\text { Participants chose } \\
\text { from } 3 \text { CD- } \\
\text { ROM-based scenar- } \\
\text { ios: deep sea diving, } \\
\text { walking through an } \\
\text { art museum, or solv- } \\
\text { ing a mystery. }\end{array}$ & $\begin{array}{l}\text { During the } \\
\text { chemotherapy infu- } \\
\text { sions, participants re- } \\
\text { ceived the VR distrac- } \\
\text { tion intervention for } \\
45-90 \text { minutes. }\end{array}$ & $\begin{array}{l}\text { SDS, STAI, } \\
\text { PFS, evalua- } \\
\text { tion of VR in- } \\
\text { tervention }\end{array}$ & $\begin{array}{l}\text { The major findings of } \\
\text { this study demonstrat- } \\
\text { ed that symptom dis- } \\
\text { tress and fatigue were } \\
\text { significantly lower } \\
\text { following chemothera- } \\
\text { py treatment during } \\
\text { which the VR interven- } \\
\text { tion was implemented. }\end{array}$ \\
\hline $\begin{array}{l}\text { Jin et al [42], Chi- } \\
\text { na }\end{array}$ & RCT & $\begin{array}{l}\text { Patients with breast } \\
\text { cancer }(\mathrm{n}=38) \text { assigned } \\
\text { to the experience group } \\
\text { received VR-based } \\
\text { training, and the other } \\
38 \text { patients with breast } \\
\text { cancer in the control } \\
\text { group received standard } \\
\text { physical training. }\end{array}$ & $\begin{array}{l}\text { A rehabilitation VR } \\
\text { system including a } \\
\text { video learning mod- } \\
\text { ule, an action acqui- } \\
\text { sition module, and } \\
\text { an action scoring } \\
\text { module. }\end{array}$ & $\begin{array}{l}\text { A total of } 3 \text { months, } \\
15-30 \text { minutes per } \\
\text { session, twice per day. }\end{array}$ & $\begin{array}{l}\text { Adherence, } \\
\text { ROM, the } \\
\text { climbing } \\
\text { height of fin- } \\
\text { ger, degree of } \\
\text { edema. }\end{array}$ & $\begin{array}{l}\text { The VR system with } \\
\text { auxiliary game treat- } \\
\text { ment was able to sub- } \\
\text { stantially improve } \\
\text { limb function recov- } \\
\text { ery, compliance, and } \\
\text { subjective initiative in } \\
\text { rehabilitation training, } \\
\text { and reduce the edema } \\
\text { of affected limbs } \\
(P<.05) \text {. }\end{array}$ \\
\hline
\end{tabular}




\begin{tabular}{|c|c|c|c|c|c|c|}
\hline $\begin{array}{l}\text { Author [reference], } \\
\text { country }\end{array}$ & Study design & Study sample & $\begin{array}{l}\text { Intervention meth- } \\
\text { ods }\end{array}$ & Intervention duration & $\begin{array}{l}\text { Outcome/in- } \\
\text { strument }\end{array}$ & Main results \\
\hline $\begin{array}{l}\text { Zhu et al [43], Chi- } \\
\text { na }\end{array}$ & RCT & $\begin{array}{l}\text { Patients with breast } \\
\text { cancer }(\mathrm{n}=80) \text { who } \\
\text { were randomly assigned } \\
\text { to the experience group } \\
\text { received VR-based } \\
\text { training, while the con- } \\
\text { trol group received } \\
\text { standard physical train- } \\
\text { ing. }\end{array}$ & $\begin{array}{l}\text { Patients received } \\
\text { VR-based shoulder } \\
\text { and hand rehabilita- } \\
\text { tion exercises. }\end{array}$ & $\begin{array}{l}\text { A total of } 3 \text { months, } \\
15-30 \text { minutes per } \\
\text { session, twice per day. }\end{array}$ & $\begin{array}{l}\text { Adherence, } \\
\text { ROM, the } \\
\text { climbing } \\
\text { height of fin- } \\
\text { ger, incidence } \\
\text { of lymphede- } \\
\text { ma }\end{array}$ & $\begin{array}{l}\text { The VR rehabilitation } \\
\text { system improved limb } \\
\text { function recovery, } \\
\text { compliance, and re- } \\
\text { duced the incidence of } \\
\text { lymphedema }(P<.05) \text {. }\end{array}$ \\
\hline $\begin{array}{l}\text { Chen et al [44], } \\
\text { China }\end{array}$ & Pre-posttest & $\begin{array}{l}\text { Patients with breast } \\
\text { cancer }(\mathrm{n}=80) \text { with } \\
\text { cognitive impairment } \\
\text { after chemotherapy. }\end{array}$ & $\begin{array}{l}\text { The } 80 \text { patients re- } \\
\text { ceived virtual cogni- } \\
\text { tive intervention } \\
\text { training. }\end{array}$ & $\begin{array}{l}\text { An 8-week interven- } \\
\text { tion }\end{array}$ & $\begin{array}{l}\text { MoCA }^{\mathrm{z}} \text {, activ- } \\
\text { ities of daily } \\
\text { living }\end{array}$ & $\begin{array}{l}\text { The scores of the } \\
\text { Montreal Cognitive } \\
\text { Assessment Scale in- } \\
\text { creased significantly } \\
\text { and the scores of ADL } \\
\text { were lower than those } \\
\text { before the interven- } \\
\text { tion }(P<.05) \text {. }\end{array}$ \\
\hline
\end{tabular}

${ }^{\mathrm{a}} \mathrm{RCT}$ : randomized controlled trial.

${ }^{\mathrm{b}} \mathrm{VR}$ : virtual reality.

${ }^{\mathrm{c}}$ VAS: visual analog scale.

${ }^{\mathrm{d}} \mathrm{ROM}$ : range of motion.

e DASH: disability of the arm, shoulder, and hand.

$\mathrm{f}_{\text {TKS: Tampa Scale of Kinesiophobia. }}$

$\mathrm{g}_{\mathrm{SAI}}$ : State Anxiety Inventory.

${ }^{\mathrm{h}}$ SV-POMS: short version of Profile of Mood States.

${ }^{\mathrm{i}}$ VRSQ: Virtual Reality Symptom Questionnaire.

${ }^{\mathrm{j}}$ ITC-SOPI: Independent Television Commission-Sense of Presence Inventory.

${ }^{\mathrm{k}} \mathrm{QC}$ : a questionnaire on cybersickness.

${ }^{1} \mathrm{RT}$ : radiation therapy.

${ }^{m}$ VERT: Virtual Environment for Radiotherapy Training.

${ }^{\mathrm{n}}$ STAI: State-Trait Anxiety Inventory.

${ }^{\circ}$ MMSE: Mini-Mental State Examination.

PBDI-II: Beck Depression Inventory, Second Edition.

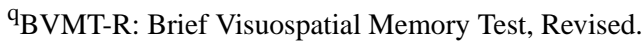

${ }^{\mathrm{r}}$ TMT-A: Trail Making Test A.

STMT-B: Trail Making Test B.

${ }^{t}$ NAB: Neuropsychological Assessment Battery.

u NPRS: Numeric Pain Rating Scale.

${ }^{\mathrm{v}}$ HVLT-R: Hopkins Verbal Learning Test, Revised.

${ }^{\mathrm{w}} \mathrm{PHQ}-9$ : Patient Health Questionnaire.

${ }^{\mathrm{x}}$ PFS: Piper Fatigue Scale.

${ }^{y_{S D S}}$ : Symptom Distress Scale.

${ }^{\mathrm{z} M o C A}$ : Montreal Cognitive Assessment.

\section{Assessment of the Risk of Bias of the Studies Included in the Review}

The results of the assessment of risk of bias are presented in Figures 2 and 3 and Table 3 . The Cochrane risk of bias tool was used to assess the quality of the included RCTs. For RCTs, allocation concealment and blinding will not seriously influence the selection of patients and the measurement of outcomes. Two of the 6 RCTs reported randomized methods in detail [16,22], while the remaining 4 trials did not provide the methods of sequence generation, nor demonstrated that the participants were recruited randomly. None of the trials provided concealment methods, except 1 trial that reported the use of anonymization by placing numbers into opaque, sealed envelopes to conceal the allocation sequence [22]. In all trials, no blind method was used on participants due to the particularity of the intervention methods. None of the trials reported employing blinding of assessors, except for 1 trial that reported the person who collected the data [16]. Only 3 studies performed power calculations and reported adequate statistical power $[16,22,41]$, while the other studies did not perform power calculations and were without dropouts $[15,42,43]$.

ROBINS-I was used to assess the risk of non-RCTs. Four studies $[14,17,40,44]$ had a moderate risk of bias, with confounding, 
outcome measurement, and selective reporting being the primary sources. Two studies [30,39] had a critical risk of bias due to missing data. The risk of selection bias was judged to be low for all studies. A detailed list of the risk of bias assessments is provided in Table 3.

Figure 2. Risk of bias analysis of included randomized controlled trials.

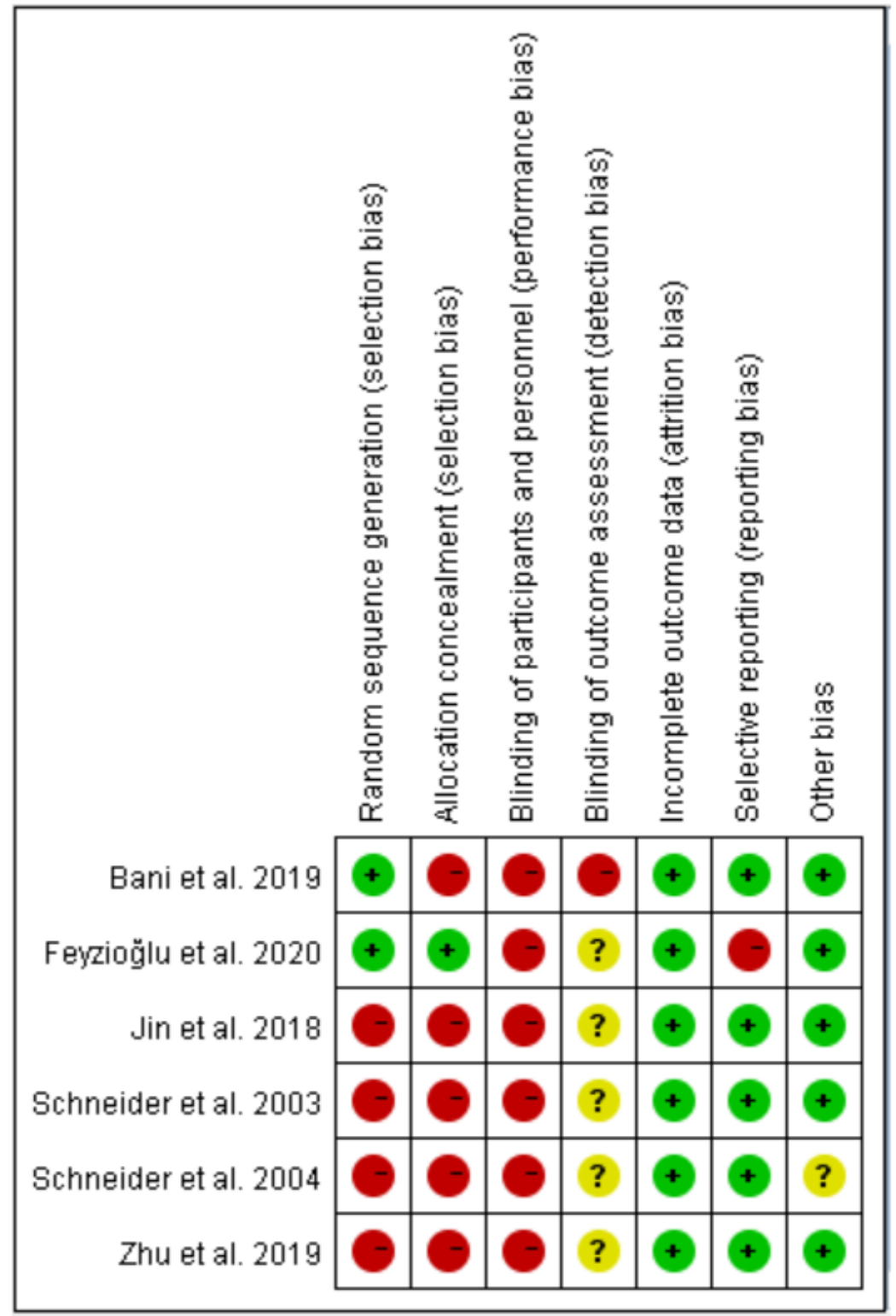


Figure 3. Overall risk of bias analysis of randomized controlled trials.

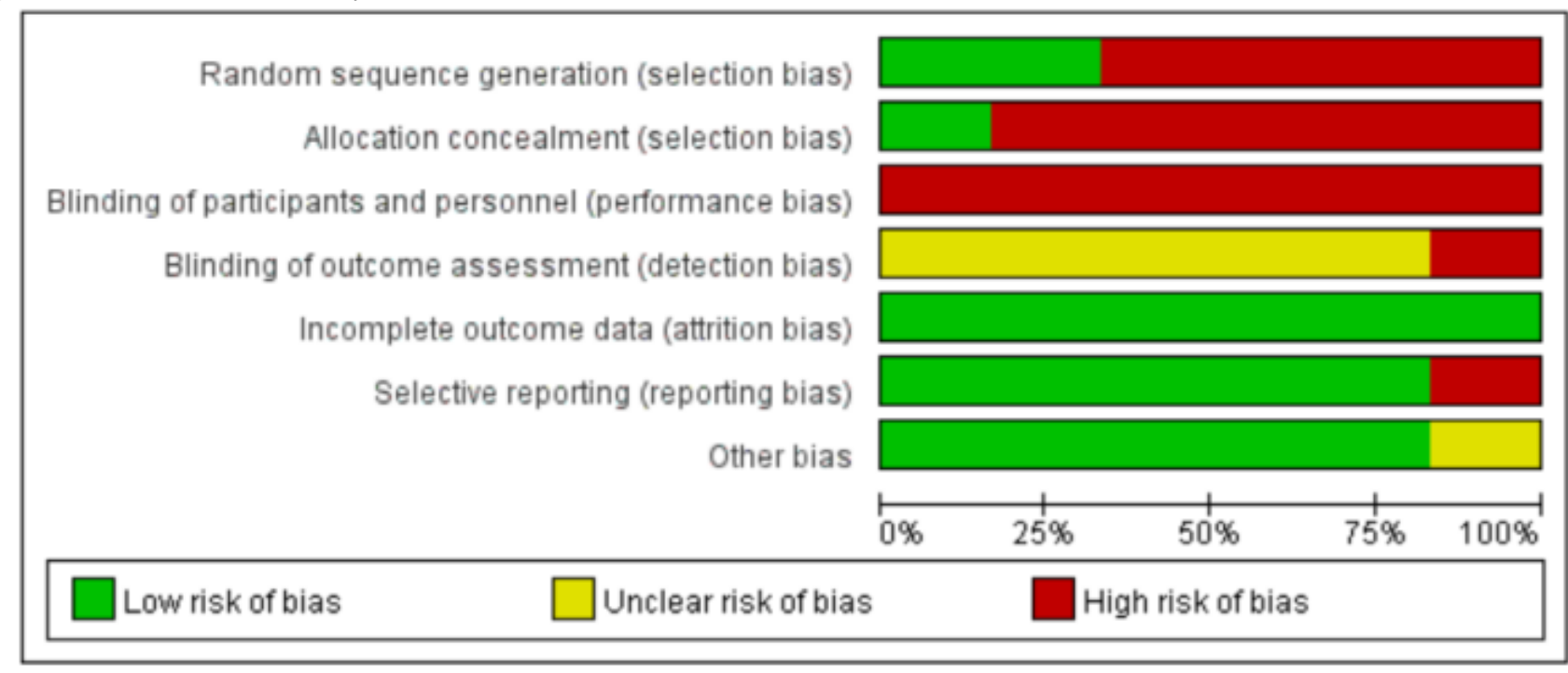

Table 3. Overall risk of bias analysis of the nonrandomized controlled trials.

\begin{tabular}{|c|c|c|c|c|c|c|c|c|}
\hline Study & $\begin{array}{l}\text { Bias due to } \\
\text { confounding }\end{array}$ & $\begin{array}{l}\text { Selec- } \\
\text { tion bias }\end{array}$ & $\begin{array}{l}\text { Bias in classifi- } \\
\text { cation of inter- } \\
\text { ventions }\end{array}$ & $\begin{array}{l}\text { Bias due to devia- } \\
\text { tions from intended } \\
\text { interventions }\end{array}$ & $\begin{array}{l}\text { Bias due to } \\
\text { missing data }\end{array}$ & $\begin{array}{l}\text { Bias in measure- } \\
\text { ment of out- } \\
\text { comes }\end{array}$ & $\begin{array}{l}\text { Bias in selec- } \\
\text { tion of the re- } \\
\text { ported result }\end{array}$ & Overall bias \\
\hline $\begin{array}{l}\text { Chirico et al } \\
{[14]}\end{array}$ & Moderate & Low & Low & Low & Low & Moderate & Moderate & Moderate \\
\hline $\begin{array}{l}\text { Atef et al } \\
\text { [39] }\end{array}$ & Moderate & Low & Low & Moderate & Critical & Low & Low & Critical \\
\hline $\begin{array}{l}\text { Buche et al } \\
{[17]}\end{array}$ & Moderate & Low & Low & Moderate & Moderate & Moderate & Moderate & Moderate \\
\hline $\begin{array}{l}\text { Jimenez et al } \\
{[40]}\end{array}$ & Moderate & Low & Low & Moderate & Moderate & Moderate & Moderate & Moderate \\
\hline $\begin{array}{l}\text { House et al } \\
{[30]}\end{array}$ & Moderate & Low & Low & Serious & Critical & Moderate & Moderate & Critical \\
\hline $\begin{array}{l}\text { Chen et al } \\
\text { [44] }\end{array}$ & Moderate & Low & Low & Low & Low & Moderate & Moderate & Moderate \\
\hline
\end{tabular}

\section{Effects of Interventions}

\section{Shoulder Range of Motion}

A meta-analysis of 4 studies [22,30,42,43] suggested statistically significant results for VR-based interventions for upper shoulder ROM. ROM was measured in degrees using a digital goniometer. We observed that VR-based interventions were more effective than standard training, as shown in Figure 4. The statistical analysis showed significant results for flexion (standard mean difference [SMD] $1.79 ; 95 \%$ CI 0.55 to 3.03; $P=.005$ ), extension (SMD 1.54; $95 \%$ CI 0.83 to $2.25 ; P<.001$ ), abduction (MD 17.53; 95\% CI 14.33 to $20.72 ; P<.001$ ), adduction (MD 15.98; 95\% CI 14.02 to $17.94 ; P<.001$ ), internal rotation (MD 7.12; 95\% CI 5.54 to $8.70 ; P<.001$ ), and external rotation (SMD $0.96 ; 95 \%$ CI 0.62 to $1.29 ; P<.001$ ). 
Figure 4. Forest plot assessing the effectiveness of using virtual reality-based interventions on shoulder range of motion.

Flexion

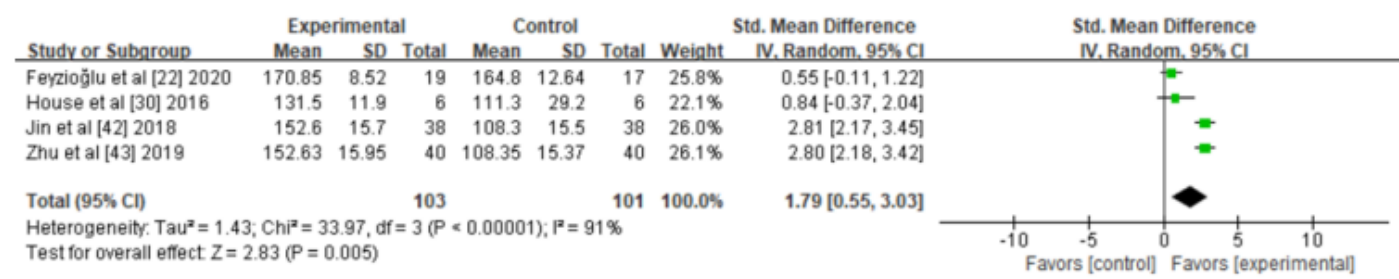

\section{Extension}

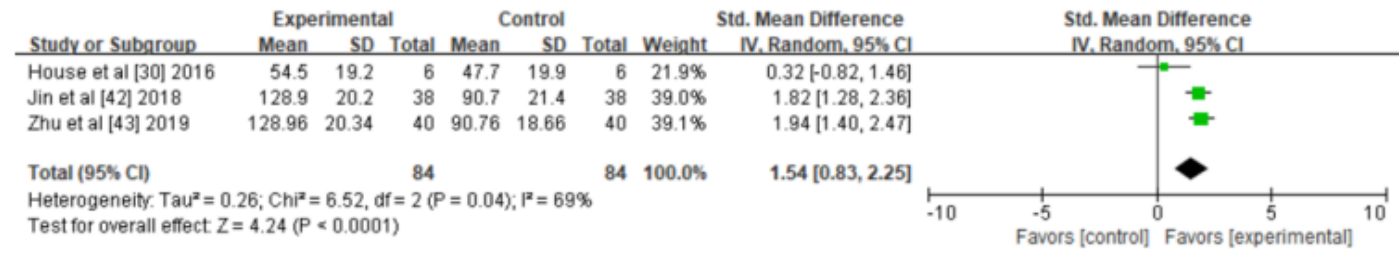

Abduction

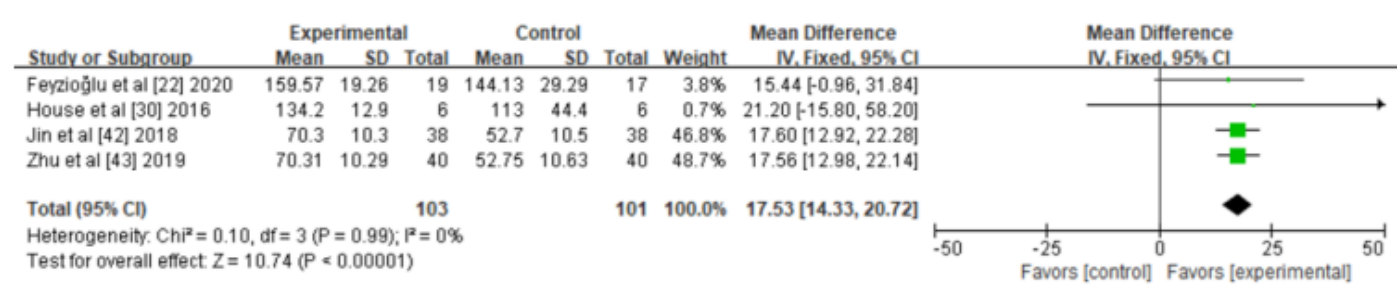

Adduction

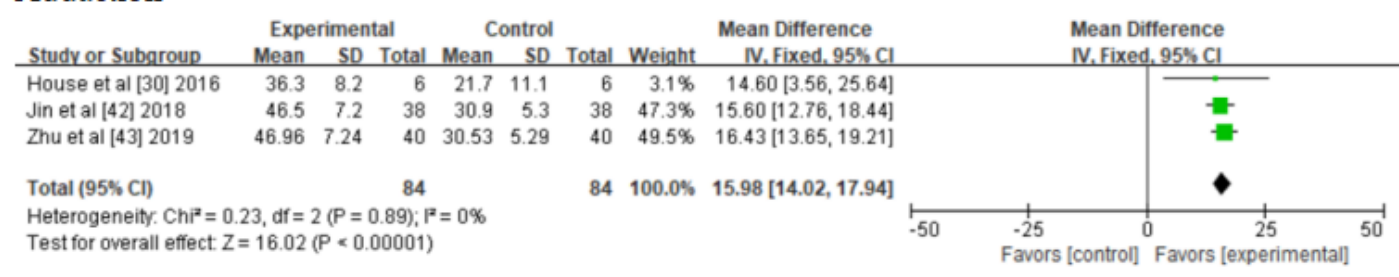

Internal rotation

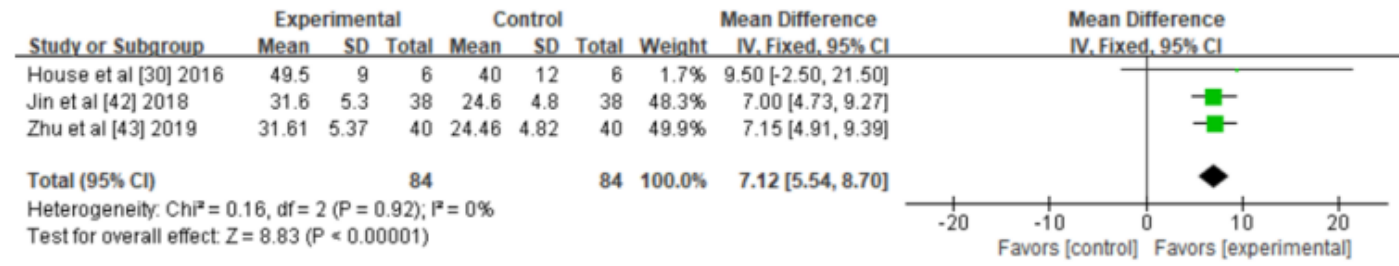

External rotation

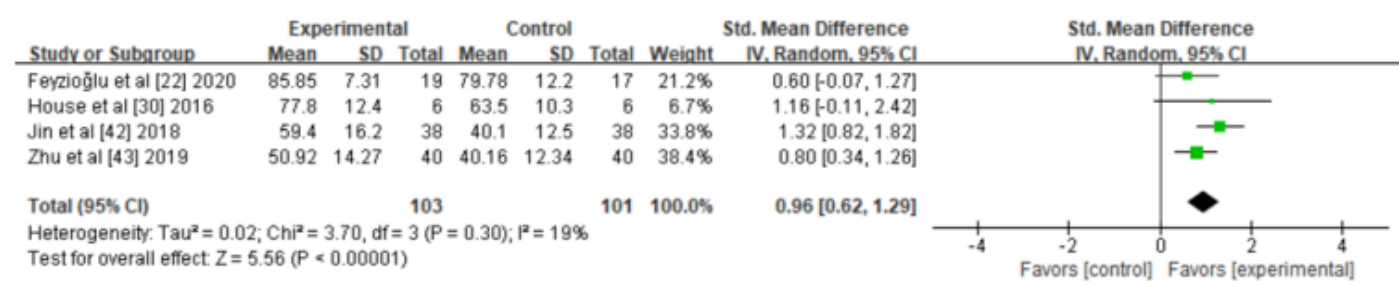

\section{Hand Grip Strength}

Two studies [22,30] measured grip strength. The Saehan hydraulic hand dynamometer was used to measure grip strength. According to the $I^{2}$ statistic, $0 \%$ of variation across studies was due to heterogeneity. This homogeneity was confirmed by the chi-square test $(P=.50)$. A fixed-effect model was fitted. The study by House et al [30] reported better results than that by Feyzioğlu et al [22]. We observed that VR-based interventions were more effective than standard training. However, the overall result of this meta-analysis was not conclusive, as shown in Figure 5. 
Figure 5. Forest plot assessing the effectiveness of using virtual reality-based interventions on hand grip strength.

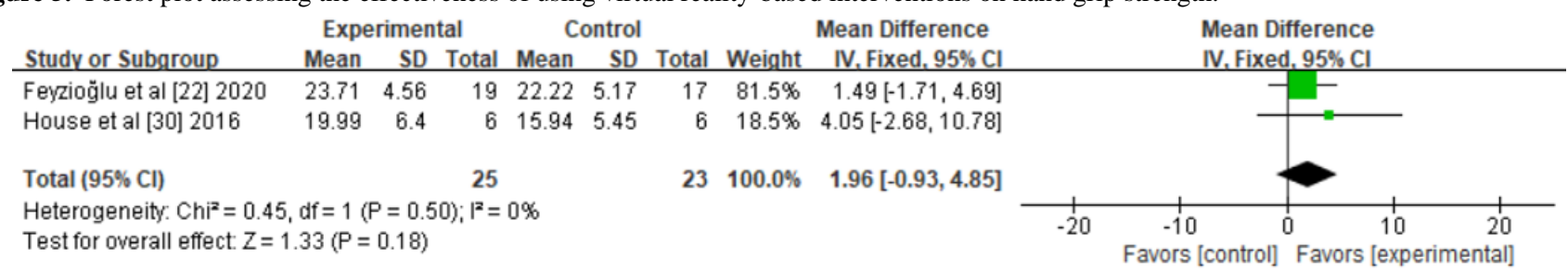

\section{Anxiety}

Of the 10 studies, 4 assessed the influence of VR-based interventions on the severity of anxiety [14,16,17,40]. The severity of anxiety was measured using the State Anxiety Inventory [14,16,17] and the State-Trait Anxiety Inventory [40]. A meta-analysis of anxiety symptoms from 4 studies produced similar positive results favoring VR-based interventions over standard education, pharmacological interventions, or noninterventions. There was substantial heterogeneity $(P<.0001$; $I^{2}=83 \%$ ), likely due to different duration, schedule, intensity, and type of interventions and methodological factors. Figure 6 shows the meta-analysis of the anxiety symptoms.

Figure 6. Forest plot assessing the effectiveness of using virtual reality-based interventions on anxiety.

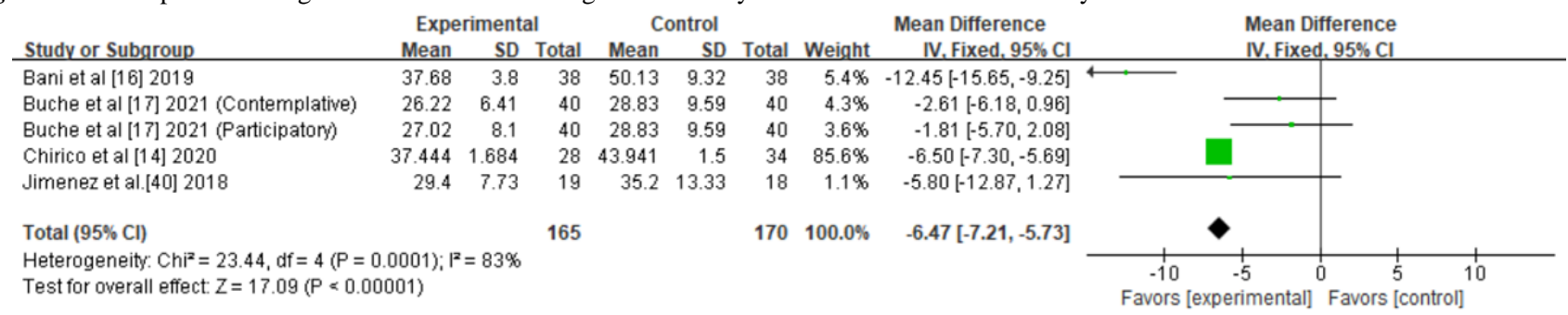

\section{Depression}

Of the 10 studies, 2 assessed the influence of VR-based interventions on the severity of depression $[14,30]$. The severity of depression was measured using the short version of Profile of Mood States and Beck Depression Inventory, Second Edition. A meta-analysis of depression from 2 studies produced similar positive results favoring VR-based interventions (MD -4.27 ; $95 \% \mathrm{CI}-4.64$ to $-3.91 ; P<.001)$. Figure 7 shows the meta-analysis of the depression symptoms.

Figure 7. Forest plot assessing the effect of using virtual reality-based interventions on depression.

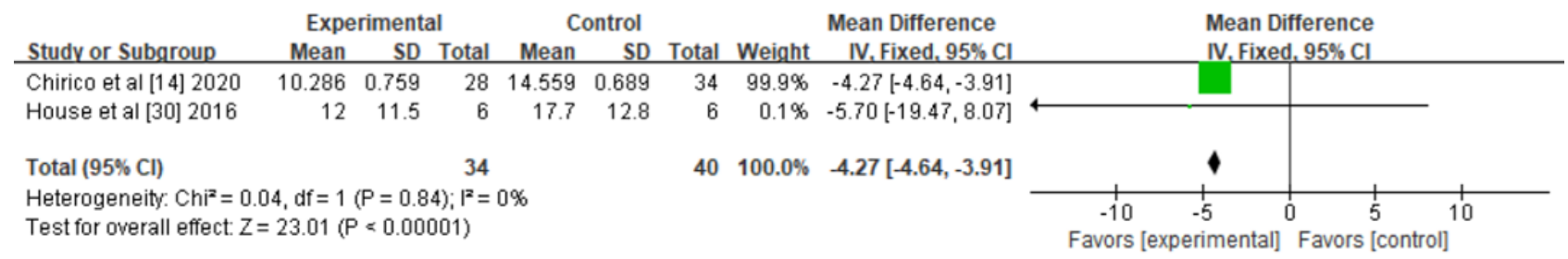

\section{Pain}

Of the 10 studies, 3 assessed the influence of VR-based interventions on the severity of pain $[16,22,30]$. The severity of pain was measured using the visual analog scale. A meta-analysis of pain from 3 studies produced similar positive results favoring VR-based interventions over standard education, pharmacological interventions, or noninterventions. There was substantial heterogeneity $\left(P<.001 ; I^{2}=87 \%\right)$, likely due to different duration, schedule, intensity, and type of interventions and methodological factors. Figure 8 presents the meta-analysis of the pain symptoms.

Figure 8. Forest plot assessing the effectiveness of using virtual reality-based interventions on pain.

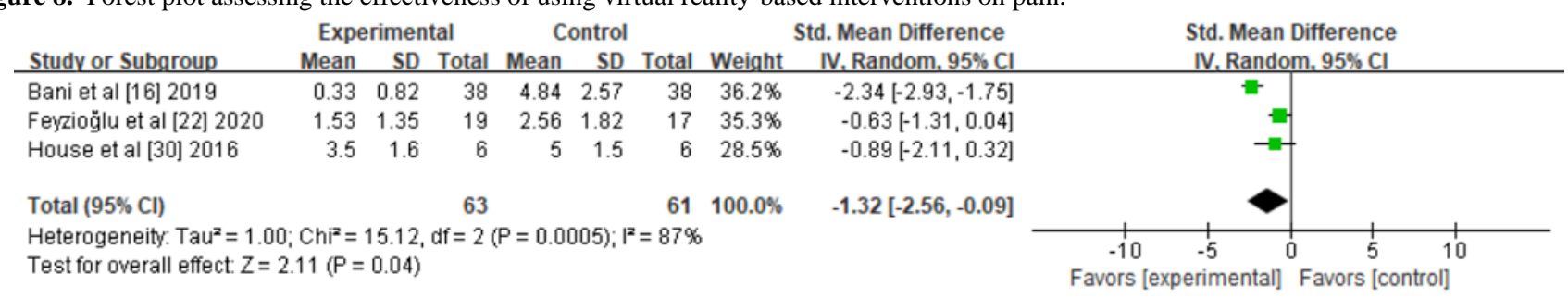

\section{Cognitive Function}

Of the 10 studies, 2 assessed the influence of VR-based interventions on cognition function $[30,44]$. Cognition function was measured using the Montreal Cognitive Assessment Scale and Brief Visuospatial Memory Test, Revised. A meta-analysis of cognitive function from 2 studies [30,44] produced similar positive results favoring VR-based interventions (MD 8.80; 
95\% CI 8.24 to $9.36 ; P<.001)$. Figure 9 presents the meta-analysis of the pain symptoms.

Figure 9. Forest plot assessing the effect of using virtual reality-based interventions on cognitive function (ie, verbal memory).

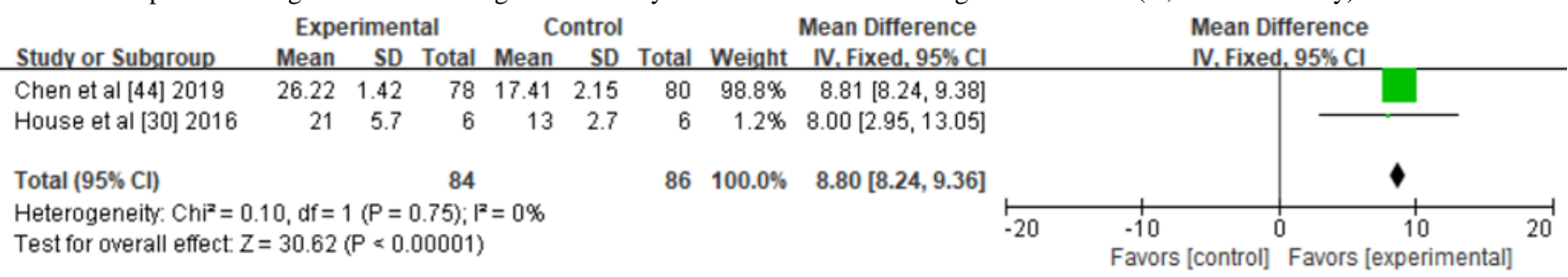

\section{Fatigue}

Chirico et al [14] reported significant changes in fatigue using the short version of the Profile of Mood States and revealed a significant difference between the 2 study groups (13.50 [SD 0.58 ] vs 15.03 [SD 0.53]; $P<.001)$. Further studies are needed to explore the efficacy of VR-based rehabilitation interventions in reducing the level of fatigue.

\section{Incidence of Complications}

Of the 10 studies, 2 [42,43] focused on the incidence of complications after surgery. Jin et al [42] reported significant differences in lymphedema incidence between their 2 study groups $(10.53 \%$ vs $42.11 \% ; P<.05)$. Zhu et al [43] reported the incidence of total complications, such as lymphedema, bleeding, effusion, and flap necrosis, between their 2 study groups (12.50\% vs $32.50 \% ; P<.05)$.

\section{Cybersickness Symptoms}

Of the 10 studies, $4[14,15,17,41]$ focused on cybersickness symptoms. Chirico et al [14] analyzed possible VR-associated cybersickness symptoms using the Virtual Reality Symptom Questionnaire. The findings showed that with the exception of a slight difficulty in concentrating, all symptoms (eg, headache, dizziness, nausea, eyestrain, drowsiness) occurred with a frequency less than 20\%. Buche et al [17] used a questionnaire on cybersickness to evaluate the possible side effects (nausea, headache, and dizziness, etc.) of VR. The findings showed that 4 out of 46 patients $(8.70 \%)$ experienced mild physical discomfort following VR. None of the patients in the other 2 studies [15,41] reported any unusual symptoms, such as dizziness, increased nausea, or visual disturbances.

\section{Fear of Movement}

Feyzioğlu et al [22] reported significant changes in fear of movement using the Tampa Kinesiophobia Scale and revealed a significant difference between the study 2 groups (29.47 [SD 5.31] vs 37.35 [SD 4.51]; $P<.001)$. Further studies are needed to explore the efficacy of VR-based rehabilitation interventions in reducing the level of kinesiophobia.

\section{Discussion}

\section{Principal Findings}

This research aimed to use qualitative and quantitative methods to evaluate the effectiveness of VR-based interventions in the rehabilitation management of patients with breast cancer. Twelve studies were included in the systematic review, 10 of which were included in the meta-analysis. A total of 604 participants were involved in different studies. In view of our results, we can conclude that VR-based interventions are more effective in improving the emotional, cognitive, and physical well-being of BCSs. For other outcomes (and comparators), the evidence was less compelling in improving learners' skills, attitudes, satisfaction, and patient-related outcomes.

\section{Quality of the Evidence}

For RCTs, due to the nature of the intervention, we judged the majority of studies to be at a high risk of bias for nonblinding of participants and study personnel and nonblinding of outcome assessment. Although blinding of outcome measurement would not seriously influence the results, nonblinding of participants might bias the effect [45]. For non-RCTs, most of the studies had a moderate risk of bias in confounding, outcome measurement, and selective reporting. Some studies had a serious or critical risk of bias, most frequently due to the outcome measurement, missing data, and choice of analyses, which did not allow controlling for missing data.

Moreover, the lack of randomization and power analysis to calculate the appropriate sample size, as well as different duration, schedule, intensity, and type of interventions, and different scales of measurements all contributed to the heterogeneity of the included studies. Additionally, some outcomes could not be analyzed quantitatively due to data format (eg, incidence of complications, cybersickness symptoms) or the fact that the data were only reported in 1 study (eg, fatigue, fear of movement). Furthermore, we could not assess the risk of publication bias because funnel plot-based methods are not accurate for less than 10 included studies per outcome.

\section{Overall Completeness and Applicability of the Evidence}

We identified 12 studies; however, most of them were limited by small sample sizes. Therefore, additional studies are needed to confirm our findings. We are encouraged that a number of larger RCTs are currently underway [46-52], which are likely to inform the field further.

Our findings must be viewed with caution owing to the limited number of trials with low quality. Moreover, as we only included a small number of trials, it was not feasible to conduct subanalyses regarding VR-based interventions or study design. A more empirical study is needed to determine the applicability of VR-based interventions in BCSs according to intense physical and psychological symptoms, function defects, and adverse effects. Additionally, further study is needed to standardize the contents of VR-based interventions, especially for upper limb recovery. Moreover, to successfully implement VR-based 
rehabilitation exercises into daily practice, it is better to provide detailed information on training frequency, duration of the intervention, and targeted motor skills [53].

\section{Potential Biases in the Review Process}

Although we performed extensive searches of the literature, there is a possibility that we did not identify all relevant studies. Two review authors independently completed data screening, extraction, evaluation of risk of bias, and certainty of evidence rating. Any discrepancies between the reviewers were resolved by discussion or in consultation with other reviewers in the event that disagreement persisted. Even though we contacted all relevant study authors for additional information, we did not always receive a response. Low study quality, inadequate methodological details, and significant inconsistencies across trials decrease the overall quality of the evidence. Moreover, the variability in VR-based interventions, as well as the timing, regimens, and definitions of outcome measurements all have the potential to contribute to inaccuracies in the assessment of the intervention effects.

\section{Agreement With Other Studies or Reviews}

The findings of this systematic review and meta-analysis indicated that VR-based interventions have a positive effect on physical and psychological symptom management and ROM. Our findings are a valuable extension of recently published systematic reviews and meta-analyses. Previous similar studies mainly focused on the effect of immersive or nonimmersive VR-based interventions in cancer survivors or stroke survivors; however, the results of the studies were inconsistent.

Ahmad et al [54] and Chow et al [55] reported that VR-based interventions may be more effective in the management of pain and anxiety in patients with cancer, whereas a nonsignificant difference in pain and anxiety was reported by Zeng et al [56]. By contrast, Ioannou et al [57] reported that VR-based interventions demonstrated a trend toward improvement in pain. One possible explanation for this difference is that the intervention effects of immersive and nonimmersive systems differ and that these reviews focused on cancer survivors. Moreover, different cancer survivors may have various physical and psychological symptoms that lead to variability within the findings. Therefore, it is necessary to conduct controlled trials between different interventions and populations. In addition, although no significant improvement was observed in most studies, we cannot ignore the potential health-promoting effects of VR-based interventions. In agreement with our review,
Aminov et al [58] found evidence of a significant effect in improving upper limb function using VR-based rehabilitation interventions and suggest VR as an adjunct for stroke rehabilitation.

Overall, previous reviews have presented similar conclusions to those of our review, suggesting that although the evidence is limited, it does exist. However, the results of this review should be interpreted with caution due to the limited number of controlled trials analyzed, the small sample sizes, and low methodological quality. The majority of previous reviews/meta-analyses indicate that more high certainty of evidence is needed before VR-based interventions can be considered as potential strategies for rehabilitation management in BCSs consistently.

\section{Implications for Research and Practice}

The examination of VR-based interventions is recommended to ascertain whether there is a role for technology - based exercise in improving the late and long-term side effects of breast cancer treatment. Furthermore, empirical evidence is required to provide well - substantiated recommendations regarding the frequency, duration, and content of the VR intervention. Finally, future studies on VR-based interventions could utilize more consistent reference standards, such as standardizing the frequency, duration, and content of the VR interventions. Such standardization minimizes bias and heterogeneity between studies. Future studies could focus on (1) the late and long-term side effects of breast cancer management; (2) the mechanism of symptom management; and (3) combination of VR with artificial intelligence, physiological indexes, and electroencephalogram.

\section{Conclusions}

The late and long-term side effects resulting from breast cancer treatment are persistent and prominent. The findings from this review suggest that VR has the potential to facilitate immediate and longer-term improvements in symptom management and the performance of upper extremity function following a surgery for BCSs. Although the use of VR-based interventions has expanded in the rehabilitation management of BCSs, the current evidence for using VR-based interventions for both immediate and long-term improvements among BCSs remains limited. Future trials would benefit from using multicenter data, with larger sample sizes, longer follow-up periods, and high methodological quality.

\section{Acknowledgments}

This study was supported by Central South University (Project Number 2020zzts847), Hunan Provincial Health Commission (Project Number 2020SK51104 and 202114021494), and the Science and Technology Bureau of Changsha (Project Number kq1901081).

\section{Authors' Contributions}

XB conceived the idea for the review. XB, PHFN, QC, and XL wrote the first draft of the manuscript. XB, WX, QC, ASKC, and XL were involved in the study selection, quality assessment, and data extraction. XL, PHFN, and QC conducted the statistical analysis. All authors reviewed the manuscript, contributed to critical changes, and approved the final version of the manuscript for submission. 


\section{Conflicts of Interest}

None declared.

\section{Multimedia Appendix 1}

Search Strategy.

[DOC File, 43 KB-Multimedia Appendix 1]

\section{References}

1. Sung H, Ferlay J, Siegel RL, Laversanne M, Soerjomataram I, Jemal A, et al. Global Cancer Statistics 2020: GLOBOCAN Estimates of Incidence and Mortality Worldwide for 36 Cancers in 185 Countries. CA Cancer J Clin 2021 May;71(3):209-249 [FREE Full text] [doi: $10.3322 /$ caac.21660] [Medline: $\underline{33538338}$ ]

2. Zeng H, Chen W, Zheng R, Zhang S, Ji JS, Zou X, et al. Changing cancer survival in China during 2003-15: a pooled analysis of 17 population-based cancer registries. The Lancet Global Health 2018 May;6(5):e555-e567. [doi: $10.1016 / \mathrm{s} 2214-109 x(18) 30127-\mathrm{x}]$

3. Todd BL, Feuerstein M, Gehrke A, Hydeman J, Beaupin L. Identifying the unmet needs of breast cancer patients post-primary treatment: the Cancer Survivor Profile (CSPro). J Cancer Surviv 2015 Jun;9(2):137-160. [doi: 10.1007/s11764-015-0428-0] [Medline: 25820913]

4. Lyman GH, Greenlee H, Bohlke K, Bao T, DeMichele AM, Deng GE, et al. Integrative Therapies During and After Breast Cancer Treatment: ASCO Endorsement of the SIO Clinical Practice Guideline Summary. J Clin Oncol 2018 Sep;36(25):2647-2655. [doi: 10.1200/JCO.2018.79.2721]

5. Wojcinski S, Nuengsri, Hillemanns, Schmidt, Deryal, Ertan, Degenhardt. Axillary dissection in primary breast cancer: variations of the surgical technique and influence on morbidity. Cancer Manag Res 2012;4:121-127. [doi: $10.2147 / \mathrm{cmar} . \mathrm{s} 30207]$

6. Bultz BD, Carlson LE. Emotional Distress: The Sixth Vital Sign in Cancer Care. J Clin Oncol 2005 Sep 10;23(26):6440-6441. [doi: 10.1200/jco.2005.02.3259]

7. Bultz BD, Carlson LE. Emotional distress: the sixth vital sign--future directions in cancer care. Psychooncology 2006 Feb;15(2):93-95. [doi: 10.1002/pon.1022] [Medline: 16444764]

8. Tsaras K, Papathanasiou I, Mitsi D, Veneti A, Kelesi M, Zyga S, et al. Assessment of Depression and Anxiety in Breast Cancer Patients: Prevalence and Associated Factors. Asian Pac J Cancer Prev 2018 Jun 25;19(6):1661-1669 [FREE Full text] [doi: 10.22034/APJCP.2018.19.6.1661] [Medline: 29938451]

9. Berger AM, Mooney K, Alvarez-Perez A, Breitbart WS, Carpenter KM, Cella D, National comprehensive cancer network. Cancer-Related Fatigue, Version 2.2015. J Natl Compr Canc Netw 2015 Aug;13(8):1012-1039 [FREE Full text] [doi: 10.6004/jnccn.2015.0122] [Medline: 26285247]

10. Reinertsen KV, Engebraaten O, Loge JH, Cvancarova M, Naume B, Wist E, et al. Fatigue During and After Breast Cancer Therapy-A Prospective Study. J Pain Symptom Manage 2017 Mar;53(3):551-560 [FREE Full text] [doi: 10.1016/j.jpainsymman.2016.09.011] [Medline: 28042070]

11. Abrahams HGJ, Gielissen MFM, Schmits IC, Verhagen CAHHVM, Rovers MM, Knoop H. Risk factors, prevalence, and course of severe fatigue after breast cancer treatment: a meta-analysis involving 12327 breast cancer survivors. Ann Oncol 2016 Jun;27(6):965-974 [FREE Full text] [doi: 10.1093/annonc/mdw099] [Medline: 26940687]

12. Manir KS, Bhadra K, Kumar G, Manna A, Patra NB, Sarkar SK. Fatigue in breast cancer patients on adjuvant treatment: course and prevalence. Indian J Palliat Care 2012 May;18(2):109-116 [FREE Full text] [doi: 10.4103/0973-1075.100826] [Medline: 23093826]

13. Maass SW, Roorda C, Berendsen AJ, Verhaak PF, de Bock GH. The prevalence of long-term symptoms of depression and anxiety after breast cancer treatment: A systematic review. Maturitas 2015 Sep;82(1):100-108. [doi: 10.1016/j.maturitas.2015.04.010] [Medline: 25998574]

14. Chirico A, Maiorano P, Indovina P, Milanese C, Giordano GG, Alivernini F, et al. Virtual reality and music therapy as distraction interventions to alleviate anxiety and improve mood states in breast cancer patients during chemotherapy. $\mathrm{J}$ Cell Physiol 2020 Jun;235(6):5353-5362. [doi: 10.1002/jcp.29422] [Medline: 31957873]

15. Schneider SM, Ellis M, Coombs WT, Shonkwiler EL, Folsom LC. Virtual reality intervention for older women with breast cancer. Cyberpsychol Behav 2003 Jun;6(3):301-307 [FREE Full text] [doi: 10.1089/109493103322011605] [Medline: $\underline{12855087]}$

16. Bani Mohammad E, Ahmad M. Virtual reality as a distraction technique for pain and anxiety among patients with breast cancer: A randomized control trial. Pall Supp Care 2019 Feb;17(1):29-34. [doi: 10.1017/s1478951518000639]

17. Buche H, Michel A, Piccoli C, Blanc N. Contemplating or Acting? Which Immersive Modes Should Be Favored in Virtual Reality During Physiotherapy for Breast Cancer Rehabilitation. Front Psychol 2021 Apr 8;12:631186 [FREE Full text] [doi: 10.3389/fpsyg.2021.631186] [Medline: $\underline{\text { 33897539] }}$ 
18. Baños RM, Espinoza M, García-Palacios A, Cervera JM, Esquerdo G, Barrajón E, et al. A positive psychological intervention using virtual reality for patients with advanced cancer in a hospital setting: a pilot study to assess feasibility. Support Care Cancer 2013 Jan;21(1):263-270. [doi: 10.1007/s00520-012-1520-x] [Medline: 22688373]

19. Williams ACDC, Craig KD. Updating the definition of pain. Pain 2016 Nov;157(11):2420-2423. [doi: 10.1097/j.pain.0000000000000613] [Medline: 27200490]

20. Ovayolu N, Ovayolu Ö, Serçe S, Tuna D, Pirbudak Çöçelli L, Sevinç A. Pain and quality of life in Turkish cancer patients. Nurs Health Sci 2013 Dec;15(4):437-443. [doi: 10.1111/nhs.12047] [Medline: 23480371]

21. Wang L, Cohen JC, Devasenapathy N, Hong BY, Kheyson S, Lu D, et al. Prevalence and intensity of persistent post-surgical pain following breast cancer surgery: a systematic review and meta-analysis of observational studies. Br J Anaesth 2020 Sep 09;125(3):346-357 [FREE Full text] [doi: 10.1016/j.bja.2020.04.088] [Medline: 32611524]

22. Feyzioğlu Ö, Dinçer S, Akan A, Algun ZC. Is Xbox 360 Kinect-based virtual reality training as effective as standard physiotherapy in patients undergoing breast cancer surgery? Support Care Cancer 2020 Sep;28(9):4295-4303. [doi: 10.1007/s00520-019-05287-x] [Medline: 31907649]

23. Lambert V, Boylan P, Boran L, Hicks P, Kirubakaran R, Devane D, et al. Virtual reality distraction for acute pain in children. Cochrane Database Syst Rev 2020 Oct 22;10(10):CD010686 [FREE Full text] [doi: 10.1002/14651858.CD010686.pub2] [Medline: 33089901]

24. Ostby PL, Armer JM, Smith K, Stewart BR. Patient Perceptions of Barriers to Self-Management of Breast Cancer-Related Lymphedema. West J Nurs Res 2018 Dec;40(12):1800-1817 [FREE Full text] [doi: 10.1177/0193945917744351] [Medline: 29191123]

25. DiSipio T, Rye S, Newman B, Hayes S. Incidence of unilateral arm lymphoedema after breast cancer: a systematic review and meta-analysis. The Lancet Oncology 2013 May;14(6):500-515. [doi: 10.1016/s1470-2045(13)70076-7]

26. Byun HK, Chang JS, Im SH, Kirova YM, Arsene-Henry A, Choi SH, et al. Risk of Lymphedema Following Contemporary Treatment for Breast Cancer: An Analysis of 7617 Consecutive Patients From a Multidisciplinary Perspective. Ann Surg $2021 \mathrm{Jul}$ 01;274(1):170-178. [doi: 10.1097/SLA.0000000000003491] [Medline: $\underline{31348041]}$

27. Winkels RM, Sturgeon KM, Kallan MJ, Dean LT, Zhang Z, Evangelisti M, et al. The women in steady exercise research (WISER) survivor trial: The innovative transdisciplinary design of a randomized controlled trial of exercise and weight-loss interventions among breast cancer survivors with lymphedema. Contemp Clin Trials 2017 Oct;61:63-72 [FREE Full text] [doi: 10.1016/j.cct.2017.07.017] [Medline: 28739540]

28. Ahmed RL, Prizment A, Lazovich D, Schmitz KH, Folsom AR. Lymphedema and Quality of Life in Breast Cancer Survivors: The Iowa Women's Health Study. J Clin Oncol 2008 Dec;26(35):5689-5696. [doi: 10.1200/jco.2008.16.4731]

29. Hasenoehrl T, Palma S, Ramazanova D, Kölbl H, Dorner TE, Keilani M, et al. Resistance exercise and breast cancer-related lymphedema-a systematic review update and meta-analysis. Support Care Cancer 2020 Aug;28(8):3593-3603 [FREE Full text] [doi: 10.1007/s00520-020-05521-x] [Medline: 32415386]

30. House G, Burdea G, Grampurohit N, Polistico K, Roll D, Damiani F, et al. A feasibility study to determine the benefits of upper extremity virtual rehabilitation therapy for coping with chronic pain post-cancer surgery. Br J Pain 2016 Nov;10(4):186-197 [FREE Full text] [doi: 10.1177/2049463716664370] [Medline: 27867508]

31. Janelsins MC, Kesler SR, Ahles TA, Morrow GR. Prevalence, mechanisms, and management of cancer-related cognitive impairment. Int Rev Psychiatry 2014 Feb;26(1):102-113 [FREE Full text] [doi: 10.3109/09540261.2013.864260] [Medline: 24716504]

32. Wefel JS, Kesler SR, Noll KR, Schagen SB. Clinical characteristics, pathophysiology, and management of noncentral nervous system cancer-related cognitive impairment in adults. CA Cancer J Clin 2015 Mar;65(2):123-138 [FREE Full text] [doi: 10.3322/caac.21258] [Medline: 25483452]

33. Tannock IF, Ahles TA, Ganz PA, van Dam FS. Cognitive Impairment Associated With Chemotherapy for Cancer: Report of a Workshop. J Clin Oncol 2004 Jun;22(11):2233-2239. [doi: 10.1200/jco.2004.08.094]

34. Christie LA, Acharya MM, Parihar VK, Nguyen A, Martirosian V, Limoli CL. Impaired Cognitive Function and Hippocampal Neurogenesis following Cancer Chemotherapy. Clin Cancer Res 2012 Apr;18(7):1954-1965. [doi:

10.1158/1078-0432.ccr-11-2000]

35. Moher D, Shamseer L, Clarke M, Ghersi D, Liberati A, Petticrew M, PRISMA-P Group. Preferred reporting items for systematic review and meta-analysis protocols (PRISMA-P) 2015 statement. Syst Rev 2015 Jan 01;4(1):1 [FREE Full text] [doi: 10.1186/2046-4053-4-1] [Medline: 25554246]

36. Higgins JP, Altman DG, Gøtzsche PC, Jüni P, Moher D, Oxman AD, Cochrane Bias Methods Group, Cochrane Statistical Methods Group. The Cochrane Collaboration's tool for assessing risk of bias in randomised trials. BMJ 2011 Oct 18;343:d5928 [FREE Full text] [doi: 10.1136/bmj.d5928] [Medline: 22008217]

37. Sterne JA, Hernán MA, Reeves BC, Savović J, Berkman ND, Viswanathan M, et al. ROBINS-I: a tool for assessing risk of bias in non-randomised studies of interventions. BMJ 2016 Oct 12;355:i4919 [FREE Full text] [doi: 10.1136/bmj.i4919] [Medline: 27733354]

38. Liberati A, Altman DG, Tetzlaff J, Mulrow C, Gøtzsche PC, Ioannidis JP, et al. The PRISMA statement for reporting systematic reviews and meta-analyses of studies that evaluate healthcare interventions: explanation and elaboration. BMJ 2009 Jul 21;339:b2700 [FREE Full text] [doi: 10.1136/bmj.b2700] [Medline: 19622552] 
39. Atef D, Elkeblawy MM, El-Sebaie A, Abouelnaga WAI. A quasi-randomized clinical trial: virtual reality versus proprioceptive neuromuscular facilitation for postmastectomy lymphedema. J Egypt Natl Canc Inst 2020 Jun;32(1):29. [doi: 10.1186/s43046-020-00041-5] [Medline: 32537717]

40. Jimenez YA, Cumming S, Wang W, Stuart K, Thwaites DI, Lewis SJ. Patient education using virtual reality increases knowledge and positive experience for breast cancer patients undergoing radiation therapy. Support Care Cancer 2018 Aug;26(8):2879-2888. [doi: 10.1007/s00520-018-4114-4] [Medline: 29536200]

41. Schneider SM, Prince-Paul M, Allen MJ, Silverman P, Talaba D. Virtual reality as a distraction intervention for women receiving chemotherapy. Oncol Nurs Forum 2004;31(1):81-88. [doi: 10.1188/04.ONF.81-88] [Medline: 14722591]

42. Jin A, Chen X, Zhang X, Chen J. Design and clinical application of rehabilitation VR system for breast cancer patients [in Chinese]. Chin J Nurs 2018;53(02):168-172. [doi: 10.3761/j.issn.0254-1769.2018.02.008]

43. Zhu L, Yu J, Li Q. Application of rehabilitation training virtual reality system in postoperative rehabilitation exercise for breast cancer patients [in Chinese]. Qilu J Nurs 2019;25(18):99-102. [doi: 10.3969/j.issn.1006-7256]

44. Chen X, Jin A, Zhu H, Zhang D. Application and effect of virtual cognitive rehabilitation training in breast cancer patients with cognitive impairment after chemotherapy [in Chinese]. Chin J Nurs 2019;54(05):664-668. [doi: 10.3761/j.issn.0254-1769]

45. Chen L, Cheng L, Gao W, Chen D, Wang C, Ran X. Telemedicine in Chronic Wound Management: Systematic Review And Meta-Analysis. JMIR Mhealth Uhealth 2020 Jun 25;8(6):e15574 [FREE Full text] [doi: 10.2196/15574] [Medline: $\underline{32584259]}$

46. Evaluation of the impact of the use of hypnotherapy performed by a virtual reality tool along the care pathway of patients undergoing breast cancer treatment. ClinicalTrials.gov. 2020. URL: https://clinicaltrials.gov/show/NCT04574609 [accessed 2022-01-24]

47. Virtual reality-based exercise training in radiotherapy period after breast cancer surgery. ClinicalTrials.gov. 2020. URL: https://clinicaltrials.gov/show/NCT04618120 [accessed 2022-01-24]

48. Evaluation of a pre-surgical virtual reality simulation for breast cancer surgery patients. ClinicalTrials.gov. 2020. URL: https://clinicaltrials.gov/show/NCT04544618 [accessed 2022-01-24]

49. A virtual reality-based radiation therapy education program. ClinicalTrials.gov. 2019. URL: https://clinicaltrials.gov/show/ NCT04029961 [accessed 2022-01-24]

50. Virtual reality versus proprioceptive neuromuscular facilitation on postmastectomy lymphedema. ClinicalTrials.gov. 2019. URL: https://clinicaltrials.gov/show/NCT04185181 [accessed 2022-01-24]

51. Improvement of patient experience and healthcare providers? Productivity using virtual reality in the field of radiation therapy. ClinicalTrials.gov. 2019. URL: https://clinicaltrials.gov/show/NCT04141943 [accessed 2022-01-24]

52. Effect of exercise mode in breast cancer-related lymphedema. ClinicalTrials.gov. 2021. URL: https://clinicaltrials.gov/ show/NCT04724356 [accessed 2022-01-24]

53. Dockx K, Bekkers EM, Van den Bergh V, Ginis P, Rochester L, Hausdorff JM, et al. Virtual reality for rehabilitation in Parkinson's disease. Cochrane Database Syst Rev 2016 Dec 21;12(12):CD010760 [FREE Full text] [doi: 10.1002/14651858.CD010760.pub2] [Medline: 28000926]

54. Ahmad M, Bani Mohammad E, Anshasi HA. Virtual Reality Technology for Pain and Anxiety Management among Patients with Cancer: A Systematic Review. Pain Manag Nurs 2020 Dec;21(6):601-607. [doi: 10.1016/j.pmn.2020.04.002] [Medline: 32423641]

55. Chow H, Hon J, Chua W, Chuan A. Effect of Virtual Reality Therapy in Reducing Pain and Anxiety for Cancer-Related Medical Procedures: A Systematic Narrative Review. J Pain Symptom Manage 2021 Feb;61(2):384-394. [doi:

10.1016/j.jpainsymman] [Medline: 32822755]

56. Zeng Y, Zhang JE, Cheng ASK, Cheng H, Wefel JS. Meta-Analysis of the Efficacy of Virtual Reality-Based Interventions in Cancer-Related Symptom Management. Integr Cancer Ther 2019;18:1534735419871108 [FREE Full text] [doi: 10.1177/1534735419871108] [Medline: 31441352]

57. Ioannou A, Papastavrou E, Avraamides MN, Charalambous A. Virtual Reality and Symptoms Management of Anxiety, Depression, Fatigue, and Pain: A Systematic Review. SAGE Open Nurs 2020 Aug 27;6:2377960820936163 [FREE Full text] [doi: 10.1177/2377960820936163] [Medline: $\underline{\text { 33415290] }}$

58. Aminov A, Rogers JM, Middleton S, Caeyenberghs K, Wilson PH. What do randomized controlled trials say about virtual rehabilitation in stroke? A systematic literature review and meta-analysis of upper-limb and cognitive outcomes. J Neuroeng Rehabil 2018 Mar 27;15(1):29 [FREE Full text] [doi: 10.1186/s12984-018-0370-2] [Medline: 29587853]

\section{Abbreviations}

BCRL: breast cancer-related lymphedema

BCS: breast cancer survivor

MD: mean difference

PICOS: Population, Intervention, Comparison, Outcomes and Study

PRISMA: Preferred Reporting Items for Systematic Reviews and Meta-Analyses

PROSPERO: Prospective Register of Systematic Reviews 
RCT: randomized controlled trial

ROBINS-I: Risk Of Bias In Non-randomized Studies of Interventions

ROM: range of motion

SMD: standard mean difference

VR: virtual reality

Edited by N Zary; submitted 20.06.21; peer-reviewed by DW Han, D Chambers; comments to author 03.08.21; revised version received

14.10.21; accepted 23.10.21; published 28.02.22

Please cite as:

$B u X, N g P H F, X u W$, Cheng $Q$, Chen PQ, Cheng ASK, Liu X

The Effectiveness of Virtual Reality-Based Interventions in Rehabilitation Management of Breast Cancer Survivors: Systematic Review and Meta-analysis

JMIR Serious Games 2022;10(1):e31395

URL: https://games.jmir.org/2022/1/e31395

doi: $10.2196 / 31395$

PMID: 35225817

CXiaofan Bu, Peter H F Ng, Wenjing Xu, Qinqin Cheng, Peter Q Chen, Andy S K Cheng, Xiangyu Liu. Originally published in JMIR Serious Games (https://games.jmir.org), 28.02.2022. This is an open-access article distributed under the terms of the Creative Commons Attribution License (https://creativecommons.org/licenses/by/4.0/), which permits unrestricted use, distribution, and reproduction in any medium, provided the original work, first published in JMIR Serious Games, is properly cited. The complete bibliographic information, a link to the original publication on https://games.jmir.org, as well as this copyright and license information must be included. 